\title{
Cross-cultural adaptation of Rotter's General Locus of Control instrument
}

\author{
Adaptação transcultural do instrumento de Locus of Control Geral de Rotter
}

\author{
Gabriel de Almeida Calado, ${ }^{1}$ Isadora Barazzetti Rigon, ${ }^{1}$ Jorge Luís Wollstein Moritz, ${ }^{2}$ Peter Wolf, ${ }^{2,3,4}$ Katia Lin $^{2,3}$
}

\begin{abstract}
Objective: To perform a cross-cultural adaptation of the General Locus of Control (GLoC) questionnaire, which measures where people place causation of events in their lives, i.e., if they interpret events as being the result of their own actions or external factors.

Methods: After translation and back-translation, a multidisciplinary committee judged and elaborated different versions of the GLoC questionnaire, with a focus on conceptual equivalence, content, comprehensibility and adjustment to the Brazilian socioeconomic context. The final version was tested on 71 healthy subjects, of whom 36 were reinterviewed and answered the GLoC questionnaire twice, after a mean of $73.06 \pm 74.15$ days (range $=29-359$ ).

Results: The participants' mean age was $30.82 \pm 12.83$ years (range $=18-69), 62 \%$ were women, and mean years of schooling were $12.54 \pm 4.21$. Test-retest reliability (Pearson's) was $r=$ 0.828. Internal consistency resulted in a Cronbach's alpha of 0.906 . The mean GLoC score obtained was 8.77 $\pm 3.11(n=71)$. Conclusion: The Portuguese version of the GLoC questionnaire is a faithful adaptation of Rotter's original questionnaire.

Key words: Internal-external control, transcultural, adaptation, learned helplessness.
\end{abstract}

\section{Resumo}

Objetivo: Realizar a adaptação transcultural do questionário General Locus of Control (GLoC), que avalia a que as pessoas atribuem a causa dos seus eventos de vida, isto é, se interpretam os eventos como sendo resultado de suas próprias ações ou de fatores externos.

Métodos: Após as fases de tradução e retrotradução do instrumento, uma equipe multidisciplinar julgou as versões obtidas quanto à manutenção do conceito original, compreensibilidade e clareza para o contexto socioeconômico da população brasileira. A versão final foi testada em 71 indivíduos saudáveis, dos quais 36 responderam duas vezes ao questionário, com um intervalo de 73,06 $\pm 74,15$ (29-359) dias.

Resultados: A média de idade dos participantes foi de $30,82 \pm 12,83$ anos (com variação de 18-69), 62\% eram mulheres, e o número médio de anos de escolaridade foi $12,54 \pm 4,21$. A análise de confiabilidade teste-reteste (coeficiente de correlação de Pearson) foi $r=0,828$. A análise de consistência interna resultou em um valor de Crohnbach de 0,906. O escore médio entre aplicações do teste foi de $8,77 \pm 3,11(n=71)$.

Conclusão: A versão em português do questionário GLoC é uma adaptação fiel ao instrumento original de Rotter.

Descritores: Controle interno-externo, transcultural, adaptação, desamparo adquirido.

\footnotetext{
${ }^{1}$ Faculdade de Medicina, Universidade Federal de Santa Catarina (UFSC), Florianópolis SC, Brazil. 2 Programa de Pós-Graduação em Ciências Médicas, UFSC, Florianópolis SC, Brazil. ${ }^{3}$ Serviço de Neurologia, Departamento de Clínica Médica, Hospital Universitário, UFSC, Florianópolis SC, Brazil. ${ }^{4}$ Danish Epilepsy Centre, Dianalund, Denmark.

Submitted Oct 11 2017, accepted for publication Feb 052018.

Suggested citation: Calado GA, Rigon IB, Moritz JL, Wolf P, Lin K. Cross-cultural adaptation of Rotter's General Locus of Control instrument. Trends Psychiatry Psychother. 2018;40(1):66-71. http://dx.doi.org/10.1590/2237-6089-2017-0127
} 


\section{Introduction}

The term locus of control (LoC) refers to an individual's perception of where the fundamental sense of agency over their life resides. LoC can be interpreted as taking place on a unidimensional spectrum, ranging from completely internal (belief in the self as exerting complete control over the course of one's life) to completely external (belief in the happenings of the outside world as the sole determinant of the course of one's life), such that nearly everyone could be said to possess a LoC in between these extremes. ${ }^{1,2}$

LoC is believed to be a consequence of the degree to which people assume causality between their decisions and their outcomes, which, over time, establishes and solidifies expectations regarding the relationship between behavior and consequences. It is, then, an important underlying variable to consider inside the realm of psychiatry and learning theory in general. In a clinical context, for instance, the concept of LoC could be used to better gauge a patient's perception of his role as the bearer of an illness, a participant in its treatment, influencing its outcome. Chronic and malignant conditions such as cancer, depression, and epilepsy in particular have proved focal points for LoC research. ${ }^{3-6}$ Among patients suffering from such conditions, both recent and historical literature have established frequent associations between higher scores (indicating externalized LoC) on the General Locus of Control (GLoC) questionnaire and decreased physical and mental well-being, increased anxiety, and negative correlations with prognosis. ${ }^{1-3,5-10}$

The questionnaire was developed by Rotter et al. at the University of Connecticut as an instrument to measure and quantify a person's general sense of LoC. ${ }^{1}$ The GLoC questionnaire has been validated and widely used in many different countries and languages, but still lacks a Brazilian Portuguese version. The purpose of this study was to produce a Portuguese version of the original GLoC questionnaire, tailored to the Brazilian socioeconomic context by means of crosscultural adaptation, so as to be ubiquitously understood by the local population while still remaining a faithful translation of the original document. $1,4,7,11,12$

\section{Methods}

\section{Study design and settings}

We followed the method established in previous successful cross-cultural translations of medical scales and questionnaires at Universidade Federal de Santa Catarina (UFSC), ${ }^{13}$ following the guidelines set out in the literature for such undertakings. ${ }^{11}$ All procedures were in accordance with the Code of Ethics of the World Medical Association (Declaration of Helsinki), and the study was only started after approval by the ethics committee for human research of UFSC. Informed consent was obtained from all participants before their inclusion in the protocol. ${ }^{13,14}$

In accordance with previously published guidelines, cross-cultural adaptation of the GLoC questionnaire included the following five steps: 1) translation; 2) back-translation; 3) review by an expert committee to ensure semantic, idiomatic, experiential and conceptual equivalence; 4) testing of the pre-final version; and 5) analysis of the scores. ${ }^{11,15,16}$

The original instrument was translated into Portuguese by two native Brazilian bilingual individuals with perfect knowledge of English, who were aware of the purpose of this study, resulting in two versions of the GLoC questionnaire. These two versions were sent to two independent native English-speaking translators with full knowledge of both languages, who did not know the purpose of the study and had no access to the original instrument, for back-translation. The review committee was comprised of a multidisciplinary team. This group compared the translated versions with the original in English, analyzed discrepancies, evaluated the clarity and comprehensibility of the questions, and assessed the cross-cultural equivalence with the source version of each item, in relation to the Brazilian population. Following this consensus meeting, a final version of the GLoC instrument in Portuguese was obtained. ${ }^{13}$

\section{The instrument}

The GLoC questionnaire consists of 29 multiplechoice questions, which ask the participant to choose between two statements advocating opposing views or opinions on a given subject matter. The two alternatives to these statements, $a$ and $b$, are formulated to perfectly encapsulate either an objectively internal or external GLoC viewpoint. By convention, the final score of the questionnaire is defined as the sum of all answers indicative of an external GLoC, as determined by the author. As such, the test quantifies the participant's GLoC as taking place on a scale of 0 (maximum internal GLoC) to 23 (maximum external GLoC), after excluding the answers to six questions that serve as distractors, to avoid the participant from realizing the nature and objectives of the test and minimize a possible societal expectation bias. ${ }^{1}$

\section{Participants}

In order to assess the comprehensibility and reliability of results of this Brazilian Portuguese version of the GLoC questionnaire, 71 healthy subjects were recruited to participate in the study and were applied 
the questionnaire twice, with an interval of at least 29 days, using an online form version of the questionnaire. Only 36 subjects completed both the initial test and the retest, that is, 35 patients did not reply to the retest request. Exclusion criteria were: individuals younger than 18 years of age and subjects with intellectual, psychiatric or emotional comorbidities that would prevent them from understanding and answering the questionnaire appropriately.

\section{Statistical analysis}

Statistical analysis was performed using the Statistical Package for the Social Sciences (SPSS) version 17.0. Descriptive analysis was conducted to characterize the sample. Quantitative variables were expressed as mean \pm standard deviation, and qualitative variables as percentage values. Test-retest reliability and internal consistency were assessed using Pearson's correlation and Cronbach's alpha. A p-value $<0.05$ was considered to be statistically significant.

\section{Results}

The individuals' sociodemographic variables and GLoC scores are listed in Table 1. Their age ranged from 18 to 69 years.

Table 1 - Sociodemographic characteristics and mean Brazilian Portuguese General Locus of Control questionnaire results $(n=71)$

\begin{tabular}{lc}
\hline Variable & $\mathbf{n}(\%)$ \\
\hline Gender & $27(38.0)$ \\
Male & $44(62.0)$ \\
Female & \\
& $30.82(12.83)$ \\
Age, mean (SD) & $12.54(4.21)$ \\
Years of schooling, mean (SD) & \\
& \\
Education level & $47(66.2)$ \\
$>11$ years of schooling & $24(33.8)$ \\
$\quad \leq 11$ years of schooling & \\
& \\
Socioeconomic class & \\
A, B1 and B2 & $45(63.4)$ \\
C1, C2, D and E & $26(36.6)$ \\
& \\
Total group score, mean (SD) & $8.77(3.11)$ \\
1st application score ( $\mathrm{n}=36)$ & $9.75(3.48)$ \\
$2 \mathrm{nd}$ application score $(\mathrm{n}=36)$ & $9.08(3.49)$ \\
Time (in days) between applications & $73.06(78.15)$ \\
\hline
\end{tabular}

Data presented as $\mathrm{n}(\%)$, unless otherwise specified.

$\mathrm{SD}=$ standard deviation.
Participants completed the two applications within a mean time interval of $73.06 \pm 74.15$ days, with a range of 29 to 359 days. In order to perform the Student $t$-test to assess equality between those who took shorter and longer intervals to answer the second application, participants were divided into two groups, i.e., intervals $\leq 60$ days and $>60$ days. No statistically significant difference was found between these groups, as shown in Table 2.

Also, individuals who were not retested $(n=35)$ did not differ from those who answered the questionnaire twice $(n=36)$ in terms of mean age $(29.85 \pm 11.03$ vs. $31.75 \pm 14.46 ; p=0.53$ ), gender ( 22 women in each group; $p=1.00$ ), years of schooling ( 30 subjects reached high school vs. $21 ; p=0.09)$ and socioeconomic status (27 subjects in classes A and B vs. 18; $p=0.07$ ).

Table 3 shows mean total and partial scores according to socioeconomic level and gender. There were no statistically significant differences between the scores in either application.

Regarding socioeconomic status (Table 3), individuals were grouped into two major groups according to the socioeconomic classification system of Associação Brasileira de Empresas de Pesquisa $(A B E P),{ }^{17}$ with classes $A, B 1$, and B2 grouped together forming the upper class group (45 patients, $63.40 \%$ of the total), and classes C, D and E comprising the lower socioeconomic status group (26 patients, $36.60 \%$ of the total). When comparing the mean total and partial scores obtained for each socioeconomic group, there were no statistically significant differences in the total scores of either application. ${ }^{17}$

Cronbach's alpha measure of internal reliability of the Brazilian Portuguese version of the GLoC questionnaire was 0.906 for the two test applications $(n=36)$. Pearson's correlation between the results of the two applications was 0.83 ( $p<0.001$ ), as shown in Table 4.

Table 2 - Brazilian Portuguese General Locus of Control according to time interval between applications $(n=36)$

\begin{tabular}{cccc}
\hline & Mean (SD) & $\mathbf{n}$ & $\mathbf{p}^{*}$ \\
\hline 1st application score & & & 0.76 \\
< 60 days of interval & $9.83(3.46)$ & 29 & \\
$>60$ days of interval & $9.43(3.78)$ & 7 & \\
& & & \\
2nd application score & & & 0.79 \\
$\quad$ 60 days of interval & $9.03(3.45)$ & 29 & \\
$>60$ days of interval & $9.29(3.95)$ & 7 & \\
\hline
\end{tabular}

$\mathrm{SD}=$ standard deviation.

* Student's $t$ test. 


\section{Discussion}

Our data show that this Brazilian Portuguese version of Rotter's GLoC questionnaire, in accordance with established recommendations and guidelines for cross-cultural adaptation, is a faithful adaptation of the original. The good correlation between the individuals' scores obtained on the two different applications of the questionnaire, along with the high Cronbach's alpha coefficient of internal reliability of 0.906 , indicate that

Table 3 - Brazilian Portuguese General Locus of Control according to socioeconomic level and gender

\begin{tabular}{|c|c|c|c|c|}
\hline Variable & $\mathbf{n}$ & Mean & SD & p* \\
\hline \multicolumn{5}{|l|}{ Socioeconomic level ${ }^{+}$} \\
\hline \multicolumn{5}{|l|}{ 1st application score } \\
\hline $\mathrm{A}, \mathrm{B} 1$, and $\mathrm{B} 2$ & 18 & 9.22 & 2.90 & 0.43 \\
\hline $\mathrm{C} 1, \mathrm{C} 2, \mathrm{D}$, and $\mathrm{E}$ & 18 & 10.28 & 3.98 & \\
\hline \multicolumn{5}{|l|}{ 2nd application score } \\
\hline $\mathrm{A}, \mathrm{B} 1$, and $\mathrm{B} 2$ & 18 & 8.78 & 3.34 & 0.75 \\
\hline $\mathrm{C} 1, \mathrm{C} 2, \mathrm{D}$, and $\mathrm{E}$ & 18 & 9.39 & 3.71 & \\
\hline \multicolumn{5}{|l|}{ Total group score } \\
\hline $\mathrm{A}, \mathrm{B} 1$, and $\mathrm{B} 2$ & 45 & 8.49 & 3.00 & 0.98 \\
\hline $\mathrm{C} 1, \mathrm{C} 2, \mathrm{D}$, and $\mathrm{E}$ & 26 & 9.27 & 3.30 & \\
\hline \multicolumn{5}{|l|}{ Gender } \\
\hline \multicolumn{5}{|l|}{ 1st application score } \\
\hline Male & 14 & 9.26 & 4.03 & 0.42 \\
\hline Female & 22 & 10.05 & 3.14 & \\
\hline \multicolumn{5}{|l|}{ 2nd application score } \\
\hline Male & 14 & 9.00 & 4.04 & 0.57 \\
\hline Female & 22 & 9.14 & 3.20 & \\
\hline \multicolumn{5}{|l|}{ Total group score } \\
\hline Male & 27 & 8.00 & 3.19 & 0.99 \\
\hline Female & 44 & 9.25 & 3.00 & \\
\hline
\end{tabular}

$\mathrm{SD}=$ standard deviation.

* Student's $t$-test.

+ Social stratification according to the classification of Associação Brasileira de Empresas de Pesquisa (ABEP), 2015. ${ }^{17}$ participants had a firm understanding of what was asked of them, and that their total GLoC scores remained similar after varying amounts of time. This is what would be expected from any adequate psychometric test attempting to ascertain and quantify a relatively stable underlying psychological variable, such as locus of control. ${ }^{1,11,15,16}$

The participants' mean GLoC score of 8.77 between applications is consistent with historical assessments of healthy control groups reported in previous literature. In Rotter's original paper, ${ }^{1}$ means ranged from 5.48 to 10.00. Given the different socioeconomic conditions of the populations studied by Rotter, including high school students, Peace Corps volunteers, and prisoners, this was considered a surprisingly narrow range of values, but one that has since been repeatedly shown in GLoC studies. Indeed, this trend is present among the results of the most comprehensive comparison of mean GLoC scores ever conducted, a 1995 databank analysis entitled "The Rotter Locus of Control Scale in 43 countries: a test of cultural relativity," an assessment of LoC in 9,140 businessmen used as proxies for comparison between populations of healthy controls from different countries. ${ }^{12}$ Country means in that study ranged from 7.00 to 12.61, with Brazilian participants averaging 8.96 ( $n=$ 172). It is important to note, however, that the different language versions of Rotter's GLoC questionnaire used in that study were simple professional translations of the original, constructed without oversight by the authors, and thus not subjected to the proper crosscultural adaptation process. Nevertheless, our findings, even with a comparatively small sample, are similar to that classic study. ${ }^{1,12}$

GLoC scores did not significantly correlate with age or total years of schooling. There is some evidence for such a link in the literature - mostly in studies investigating GLoC as a variable in more specific contexts, such as educational attainment over time but so far no claims to conclusive findings applicable to the general population have been made. A lack of such a correlation is interesting in that it suggests that LoC as a psychometric variable might be more

Table 4 - Pearson's correlation between separate application results, time interval, age, and years of schooling

\begin{tabular}{|c|c|c|c|c|c|c|}
\hline & \multicolumn{2}{|c|}{$\begin{array}{l}\text { Score on 1st application } \\
(n=36)\end{array}$} & \multicolumn{2}{|c|}{$\begin{array}{l}\text { Score on } 2 \text { nd application } \\
(n=36)\end{array}$} & \multicolumn{2}{|c|}{$\begin{array}{c}\text { Total group score } \\
(n=71)\end{array}$} \\
\hline & $\mathbf{r}$ & $\mathbf{p}$ & $\mathbf{r}$ & $\mathbf{p}$ & $\mathbf{r}$ & $\mathbf{p}$ \\
\hline Score on 1st application & 1 & - & 0.828 & $<0.001^{*}$ & 0.956 & $<0.001^{*}$ \\
\hline Age (years) & -0.216 & 0.205 & -0.294 & 0.082 & -0.198 & 0.098 \\
\hline Total years of schooling & -0.058 & 0.738 & 0.066 & 0.702 & -0.142 & 0.237 \\
\hline Time interval & -0.155 & 0.366 & -0.052 & 0.765 & -0.108 & 0.531 \\
\hline
\end{tabular}

* Correlation is significant at the 0.01 level (2-tailed). 
independent of extrinsic factors and stable over time than commonly postulated. This would support the view of GLOC as being related to primary personality traits, actively shaping one's world view and perceived personal societal context, as opposed to being shaped by them. ${ }^{1,18,19}$

This study did not find any statistically significant differences in GLoC scores between people in different socioeconomic classes. The theoretical background that led the investigators to hypothesize a negative correlation between GLoC scores and wealth was based on the idea that wealth, in facilitating a person's accomplishment of their goals, would make one more susceptible to the belief that their own volition is the sole agent behind both their failures and accomplishments, with little to no consideration of extrinsic factors. While evidence of socioeconomic factors as potential influencers of GLoC scores is more prevalent in the literature than other variables (such as age or education), when taken in the context of the conflicting statistical significance of such findings among other studies, our findings once again seem to indicate that LoC may play a more independent, stable role in an individual's identity. $1,4,17,18$

Finally, this study was subject to some of the limitations shared by all cross-cultural translations. These studies, more often than not, use relatively small sample sizes when compared to the original papers used in the construction of the clinical assessment tools on which they are based, as their primary objective is not to search for correlations within the available data, but rather to simply demonstrate comprehensibility and reliability of results within a different population and culture than that of the original; a task that almost always requires a comparatively small test population. In light of this, it is often difficult for these studies to replicate all the findings of the original studies, even though this does not necessarily imply a flawed adaptation process. Our study also had quite significant variability in the length of time participants took between test applications. This was largely a consequence of difficulties in maintaining contact and engagement with participants for extended periods of time, a difficulty that required multiple distinct application sessions on different groups of people to mend. To compensate for the uncertainty that this variability might have caused to test-retest reliability, participants were split into two groups based on those who had a relatively small ( $\leq 60$ days) and long (> 60 days) interval between application responses. Comparison between these groups yielded no statistically significant differences in response consistency, demonstrating the participants' results to be stable over time.

\section{Conclusion}

We conclude, therefore, that the Brazilian Portuguese cross-cultural adaptation of Rotter's GLoC questionnaire was properly constructed, in accordance to the most recent and accepted guidelines available, and that it has demonstrated more than adequate reliability and comprehensibility within the sample group studied to be considered ready for use in the Brazilian population.

\section{Acknowledgements}

Katia Lin holds a PQ2 Research Fellowship from Conselho Nacional de Desenvolvimento Científico e Tecnológico (CNPq; process no. 307861/2013-9). Isadora Barazzetti Rigon has received financial support from Programa Institucional de Bolsas de Iniciação Científica from CNPq (PIBIC/UFSC). Peter Wolf holds a Special Visiting Researcher Fellowship in Brazil - Programa Ciência sem Fronteiras from Coordenação de Aperfeiçoamento de Pessoal de Nível Superior (CAPES; project MEC/MCTI/ CAPES/CNPq/FAPs no. 88881.030478/2013-01).

\section{Disclosure}

No conflicts of interest declared concerning the publication of this article.

\section{References}

1. Rotter JB. Generalized expectancies for internal versus external control of reinforcement. Psychology Monographs: General and Applied. 1966;80:1-28.

2. Wall JB. Relationship of locus of control to self-actualization. Psychol Rep. 1970;27:282.

3. Devillis RF, Devellis BM, Wallston BS, Wallston KA. Epilepsy and learned helplessness. Basic Appl Soc Psych. 1980;1:241-53.

4. Culpin I, Stapinski L, Miles OB, Araya R, Joinson C. Exposure to socioeconomic adversity in early life and risk of depression at 18 years: the mediating role of locus of control. J Affect Disord. 2015;183:269-78.

5. Bjorklof GH, Engedal K, Selbaek G, Maia DB, Borza T, Benth JS, et al. Can depression in psychogeriatric inpatients at one year follow-up be explained by locus of control and coping strategies? Aging Ment Health. 2017;1:1-10.

6. Brown AJ, Thaker PH, Sun CC, Urbauer DL, Bruera E, Bodurka DC, et al. Nothing left to chance? The impact of locus of control on physical and mental quality of life in terminal cancer patients. Support Care Cancer. 2017;25:1985-91.

7. Rita Halpert RH. 28 Measures of Locus of Control. In: Halpert $R$, editors. The Locus of Control construct's various means of measurement: a researcher's guide to some of the more commonly used Locus of Control scales. Beach Haven, NJ: Will to Power Press; 2011. p. 96.

8. Millman ZB, Weintraub MJ, Bentley E, DeVylder JE, Mittal VA, Pitts $\mathrm{SC}$, et al. Differential relations of locus of control to perceived social stress among help-seeking adolescents at low vs. high clinical risk of psychosis. Schizophr Res. 2016;184:39-44.

9. Sperling MR, Schilling CA, Glosser D, Tracy JI, Asadi-Pooya AA. Self-perception of seizure precipitants and their relation to 
anxiety level, depression, and health locus of control in epilepsy. Seizure. 2008;17:302-7.

10. Bjorklof GH, Engedal K, Selbaek G, Maia DB, Coutinho ES, Helvik AS. Locus of control and coping strategies in older persons with and without depression. Aging Ment Health. 2016;20:831-9.

11. Beaton DE, Bombardier C, Guillemin F, Ferraz MB. Guidelines for the process of cross-cultural adaptation of self-report measures. Spine (Phila Pa 1976). 2000;25:3186-91.

12. Peter $B$. Smith FT, Shaun D. The Rotter Locus of Control scale in 43 countries: a test of cultural relativity. Int J Psychol. 1995;30:24.

13. Janzen EP, Walz R, Lin K. Cross-cultural adaptation of the SCATBI instrument for cognitive-linguistic abilities after traumatic brain injury. Arq Neuropsiquiatr. 2015;73:939-45.

14. General Assembly of the World Medical A. World Medical Association Declaration of Helsinki: ethical principles for medical research involving human subjects. J Am Coll Dent. 2014;81:14-8.

15. Guillemin F, Bombardier C, Beaton D. Cross-cultural adaptation of health-related quality of life measures: literature review and proposed guidelines. J Clin Epidemiol. 1993;46:1417-32.

16. Gorenstein C, Andrade LHSG, Zuardi AW. Escalas de avaliação clínica em psiquiatria e psicofarmacologia. São Paulo: Lemos; 2000.
17. Mazzon JA, Kamakura WA. Estratificação socioeconômica e consumo no Brasil. São Paulo: Blucher; 2016.

18. Landau R. Locus of control and socioeconomic status: does internal locus of control reflect real resources and opportunities or personal coping abilities? Soc Sci Med. 1995;41:1499-505.

19. Flouri E. Parental interest in children's education, children's selfesteem and locus of control, and later educational attainment: twenty-six year follow-up of the 1970 British Birth Cohort. Br J Educ Psychol. 2006;76:41-55.

\section{Correspondence:}

Katia Lin

Departamento de Clínica Médica, Hospital Universitário Polydoro Ernani de São Thiago

Rua Prof. Maria Flora Pausewang, s/no, $3^{\circ}$ andar, Caixa postal 5199, Campus Universitário

88040-900 - Florianópolis, SC - Brazil

Tel.: +55 (48) 37212037, Fax: +55 (48) 37219014

E-mail: katia.lin@ufsc.br 